\title{
Research Article \\ Kinetics of Thermal Degradation of Recycled Polyvinyl Chloride Resin
}

\author{
I. M. Alwaan ${ }^{1,2}$ \\ ${ }^{1}$ Materials Engineering Department, College of Engineering, Kufa University, Najaf 00964, Iraq \\ ${ }^{2}$ Faculty of Chemical Engineering, Universiti Teknologi Malaysia, Johor 81310, Malaysia \\ Correspondence should be addressed to I. M. Alwaan; ism10alw@yahoo.com
}

Received 18 August 2013; Revised 31 October 2013; Accepted 10 November 2013; Published 30 January 2014

Academic Editor: Dmitry Murzin

Copyright (C) 2014 I. M. Alwaan. This is an open access article distributed under the Creative Commons Attribution License, which permits unrestricted use, distribution, and reproduction in any medium, provided the original work is properly cited.

\begin{abstract}
The goal of this study is to find the effect of time and temperature on the thermal degradation of recycled polyvinyl chloride (PVC) resin. The isothermal rate of reaction $(r)$ of recycled PVC resin was investigated at the following temperatures to: 100, 110, 120, 130, and $140^{\circ} \mathrm{C}$ at period of times ranging from 10 to $50 \mathrm{~min}$. The result shows that the rate of reaction $(r)$ of recycled PVC increases with increasing temperatures. The reaction rate constant $(K)$ for temperatures ranging from 100 to $140^{\circ} \mathrm{C}$ was doubled from $0.028-$ $0.056 \mathrm{~mol} \cdot \mathrm{L}^{-1} \cdot \mathrm{S}^{-1}$. The process was found to be zero order reaction at all range of temperatures $100-140^{\circ} \mathrm{C}$. The activation energy of the thermal weight loss was calculated at different temperatures $\left(E / R=2739.5^{\circ} \mathrm{K}\right)$. The average enthalpy and entropy of reaction at temperature of $298^{\circ} \mathrm{K}$ were determined.
\end{abstract}

\section{Introduction}

Polyvinyl chloride (PVC) is one of the most commonly used thermoplastic materials with respect to the worldwide polymer consumption. At present, demand for PVC exceeds 35 million tons annually, and it is rated second only after polyethylene in consumption by volume. Currently, PVC is applied in a variety of products including packaging, medical devices, food, and also long-life applications such as pipes, window frames, cable insulation, floors coverings, and roofing sheets [1].

Previously, studies conducted on the thermal stability of the polyvinyl chloride showed that the stability of PVC resin mixed with organic tin and hydrotalcite was better than that of the PVC resin mixed with organic Tin alone [2]. The degradation temperature of $1-2 \mathrm{wt} \% \mathrm{PVC}$ in the presence of $\mathrm{PE}, \mathrm{PP}$, and $\mathrm{PS}$ was found to be $360-440^{\circ} \mathrm{C}$ depending on the rate of feeding [3]. The $\mathrm{HCl}$ scavenging effect of particulate fillers such as red mud (RM), $\mathrm{CaCO}_{3}$, and dolomite on the thermal degradation of PVC was investigated by thermogravimetry/mass spectrometry (TG/MS) [4]. Complex polymer mixtures PVC and other commodity plastics were thermally degraded at 450 in the presence of epoxy type flame retardant (ABS-Br) [5-8]. The thermal behaviour of
PVC/epoxidized liquid natural rubber (ELNR) and zinc soaps of rubber seed oil (RSO) and epoxidised rubber seed oil (ERSO) as stabilizers was investigated $[9,10]$.

Moreover, activation energy for the degradation of series of solution-cast blends of polyvinyl chloride/epoxidised liquid natural rubber (ELNR) was studied and the results were $73,41,73$, and $77.25 \mathrm{KJ} / \mathrm{mol}$ for $100 / 0,70 / 30,50 / 50$, and $30 / 70$ PVC/ELNR-20, respectively, where activation energy of 30/70 $\mathrm{PVC} / \mathrm{LNR}$ was $35 \mathrm{~kJ} / \mathrm{mol}$ [9]. The activation energy of PVC was calculated in the mixture to give a value of $11.2 \mathrm{~kJ} / \mathrm{mol}$ for a $\mathrm{Ca} / \mathrm{Zn}$-stabilised material and $29.1 \mathrm{~kJ} / \mathrm{mol}$ for other materials containing a mixture of $\mathrm{Ba} / \mathrm{Cd}$ and $\mathrm{Pb}$ stabilisers or pure $\mathrm{Pb}$ stabilizer [11]. Oxidative degradation of rigidPVC pellets (R-PVC) with oxygen was carried out and the apparent rate of oxidative degradation of R-PVC progressed as a zero order reaction, and the apparent activation energy was $38.5 \mathrm{~kJ} / \mathrm{mol}$ [12].

Also, other techniques of PVC degradation like photocatalysis $[13,14], \gamma$ rays $\left({ }^{60} \mathrm{Co}\right.$ ) at high doses (up to 4 MGy) [15] and tungstophosphoric acid (HPW) [16] were studied by researchers.

The goal of this study is to know how the PVC resin is affected by different temperatures $\left(100-140^{\circ} \mathrm{C}\right)$ and at different periods of time $(10,20,30,40$, and $50 \mathrm{~min})$. So we 
TABLE 1: The rate of reaction $(\mathrm{g} / \mathrm{min})$ of PVC resin at different times (min) and at different temperatures $\left(100-140^{\circ} \mathrm{C}\right)$.

\begin{tabular}{lccccc}
\hline Time (min) & & Rate of reaction $(\mathrm{g} / \mathrm{min})$ & & At curing \\
& $\begin{array}{c}\text { At curing } \\
T=100^{\circ} \mathrm{C}\end{array}$ & $\begin{array}{c}\text { At curing } \\
T=110^{\circ} \mathrm{C}\end{array}$ & $\begin{array}{c}\text { At curing } \\
T=120^{\circ} \mathrm{C}\end{array}$ & $\begin{array}{c}\text { At curing } \\
T=130^{\circ} \mathrm{C}\end{array}$ \\
\hline 10 & 0.01784 & 0.02522 & 0.05377 & 0.0617 \\
20 & 0.028795 & 0.03975 & 0.04404 & 0.049285 & 0.0503 \\
30 & 0.02371 & 0.029233 & 0.035667 & 0.038073 & 0.0401 \\
40 & 0.0275 & 0.029175 & 0.032135 & 0.0366 & 0.0395 \\
\hline 0 & 0.031422 & 0.03282 & 0.035626 & 0.043858 \\
\hline
\end{tabular}

know how the PVC resin bears the temperature from 100 to $140^{\circ} \mathrm{C}$ with and without problems of it being damaged in the recycling process. To know the mechanism of the degradation reaction, the order of reaction, the rate of reaction constant, and the activation energy were calculated at different temperatures $\left(100-140^{\circ} \mathrm{C}\right)$ and at different periods of time $(10,20,30,40$, and $50 \mathrm{~min})$.

\section{Experiment}

2.1. Materials. Recycled polyvinyl chloride (PVC) was supplied from Hose Jeihoon Plast Company in Iran.

2.2. Processing. The following is the procedure to degrade the recycled polyvinyl chloride with temperatures and times.

It was weighted of empty crucible (ceramic crucible) and crucible with recycled PVC, where the state of the recycled PVC samples was a sheet with the dimensions: $1 \mathrm{~cm}$ in length, $1 \mathrm{~cm}$ in width, and $0.2 \mathrm{~cm}$ in thickness. Therefore, the initial weight can be determined by the following law:

$$
W_{o}=W_{1}-W_{2}
$$

where $W_{1}=$ weight of the crucible with the sample of recycled PVC and $W_{2}=$ weight of the empty crucible.

After that the crucible with recycled PVC samples was put in the furnace under atmospheric air to the required heating time and temperature. When degradation was completed, the recycled PVC sample was removed from the furnace and cooled to estimate the weight loss of the recycled PVC.

The above procedure was repeated for every degrading sample of recycled PVC in each temperature and time.

\section{Results and Discussion}

The kinetics of thermal degradation of PVC resin was studied at various temperatures $\left(100-140^{\circ} \mathrm{C}\right)$ and during various times $(10-50 \mathrm{~min})$. The reaction rate of recycled PVC was experimentally determined using the relation [17]

$$
r=\frac{\Delta w}{t}
$$

where $\Delta w$ is the weight loss and $t$ is the period of time during which the specimen remains in furnace, as shown in Table 1.
To calculate the order of reaction $(n)$ for the recycled PVC, a plot of $\ln (r)$ versus $\ln (C)$ was done according to the following equations [18]:

$$
r=\frac{d C}{d t}=K \cdot C^{n}
$$

where $r=$ the rate of reaction, $C=$ concentration of no degraded material, $K=$ the rate of reaction constant, and $n=$ the order of reaction. Take the $\ln$ function to both sides of (3) to obtain

$$
\ln (r)=n \ln (C)+\ln (K)
$$

Plotting $\ln (r)$ versus $\ln (C)$ according to (4) gave a straight line. The slope represents the order of reaction $(n)$ while the intercept represents the rate of reaction constant $(\ln (K))$, as shown in Figure 1.

The rate of the reaction equations at different temperatures $\left(100-140^{\circ} \mathrm{C}\right)$ was obtained from Figure 1 and was reported as follows:

$$
\begin{aligned}
& \ln (r)=0.242 \ln (C)-3.5738, \quad \text { at } T=100^{\circ} \mathrm{C}, \\
& \ln (r)=0.1247 \ln (C)-3.4506, \quad \text { at } T=110^{\circ} \mathrm{C}, \\
& \ln (r)=-0.4058 \ln (C)-3.2183, \quad \text { at } T=120^{\circ} \mathrm{C}, \\
& \ln (r)=-0.4327 \ln (C)-3.0603, \quad \text { at } T=130^{\circ} \mathrm{C} \\
& \ln (r)=-0.5397 \ln (C)-2.8772, \quad \text { at } T=140^{\circ} \mathrm{C} .
\end{aligned}
$$

The order of reaction of thermal degradation of recycled PVC resin was between 0.2421 th and -0.539 th, as shown in (5), at the range of temperatures $\left(100-140^{\circ} \mathrm{C}\right)$. Since there is no negative order reaction and 0.2421 th or 0.124 th is very low, therefore the reaction is more likely to be zero order reaction and it was proved by plotting the data according to zero, first, and second order reaction equations [18] and the results were that plotting according to zero order reaction equation gave a straight line while the others gave curves, as shown in Figure 2. Therefore, it can be concluded that the order of reaction was zero order. A similar result was reported by Yoshioka et al. [12], where the reaction order of oxidative 

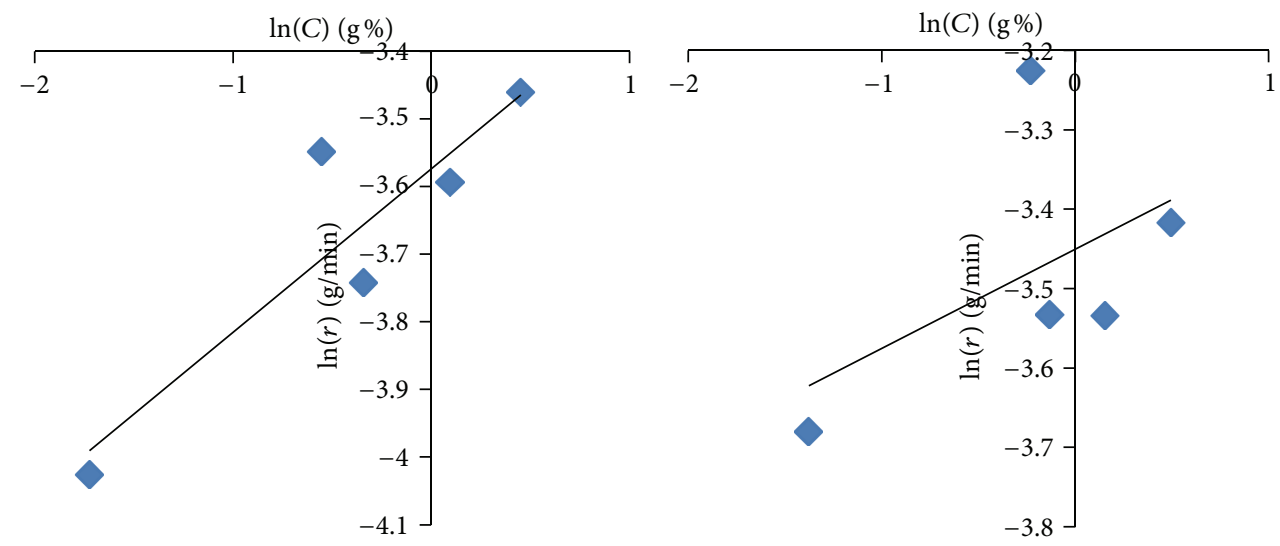

$\ln (r)=0.242 \ln (C)-3.5738$

$\ln (r)=0.1247 \ln (C)-3.4506$

$\ln (r) \mathrm{T}=100^{\circ} \mathrm{C}$

$\rightarrow \ln (r) \mathrm{T}=110^{\circ} \mathrm{C}$

(a)

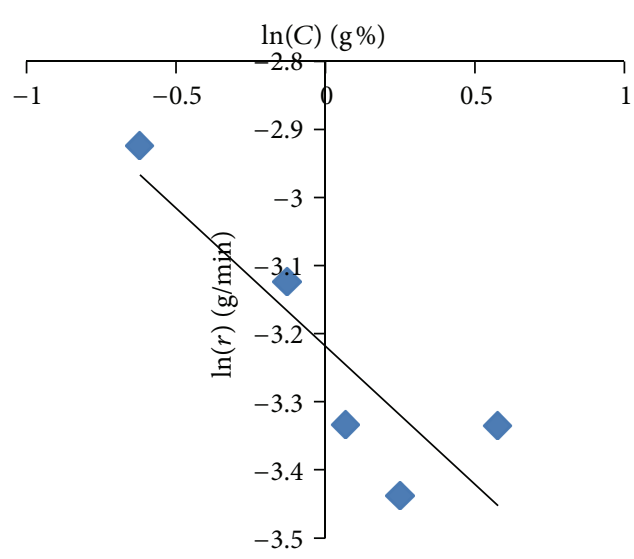

$\ln (r)=-0.4058 \ln (C)-3.2183$

$\ln (r) T=120^{\circ} \mathrm{C}$ (b)

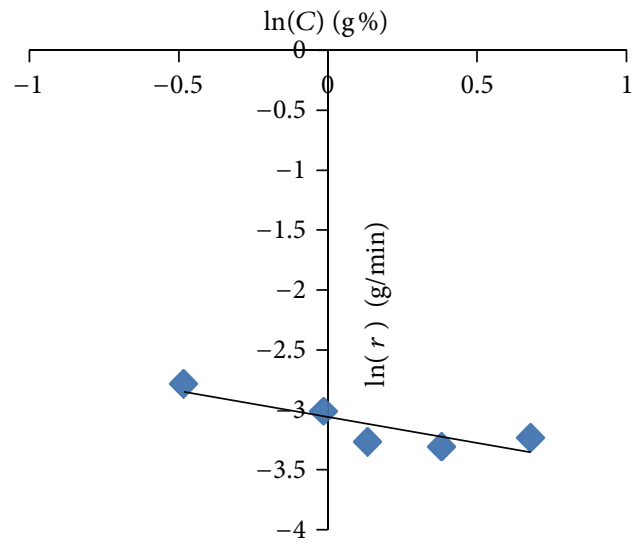

$\ln (r)=-0.4327 \ln (C)-3.0603$

$\ln (r) T=130^{\circ} \mathrm{C}$

(c)

(d)

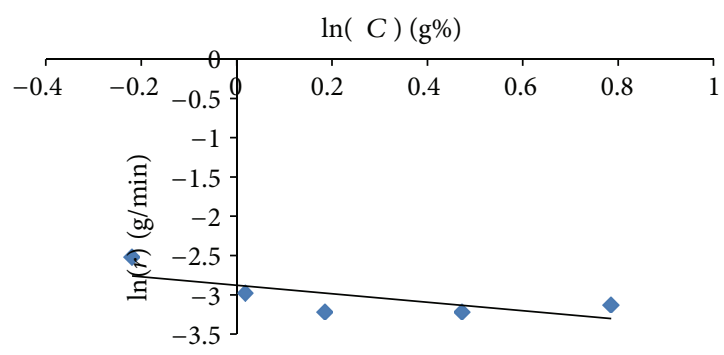

$\ln (r)=-0.5397 \ln (C)-2.8772$

$\ln (r) T=140^{\circ} \mathrm{C}$

(e)

Figure 1: The $\ln (r)$ versus $\ln (C)$ of PVC resin at different times (min) and at different temperatures $\left(100-140^{\circ} \mathrm{C}\right)$. 


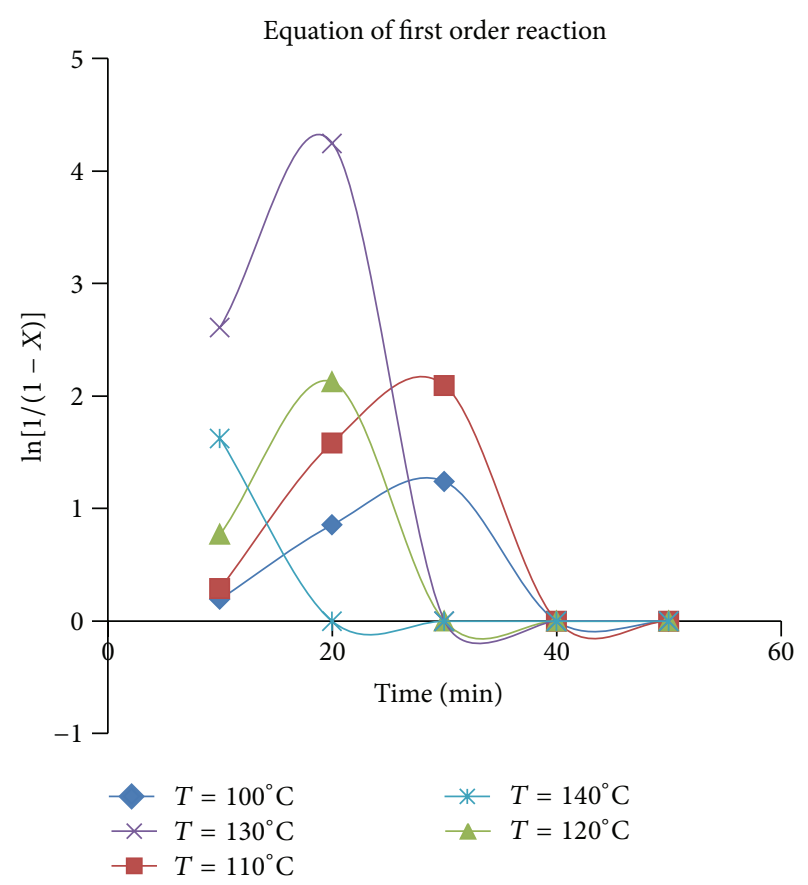

(a)

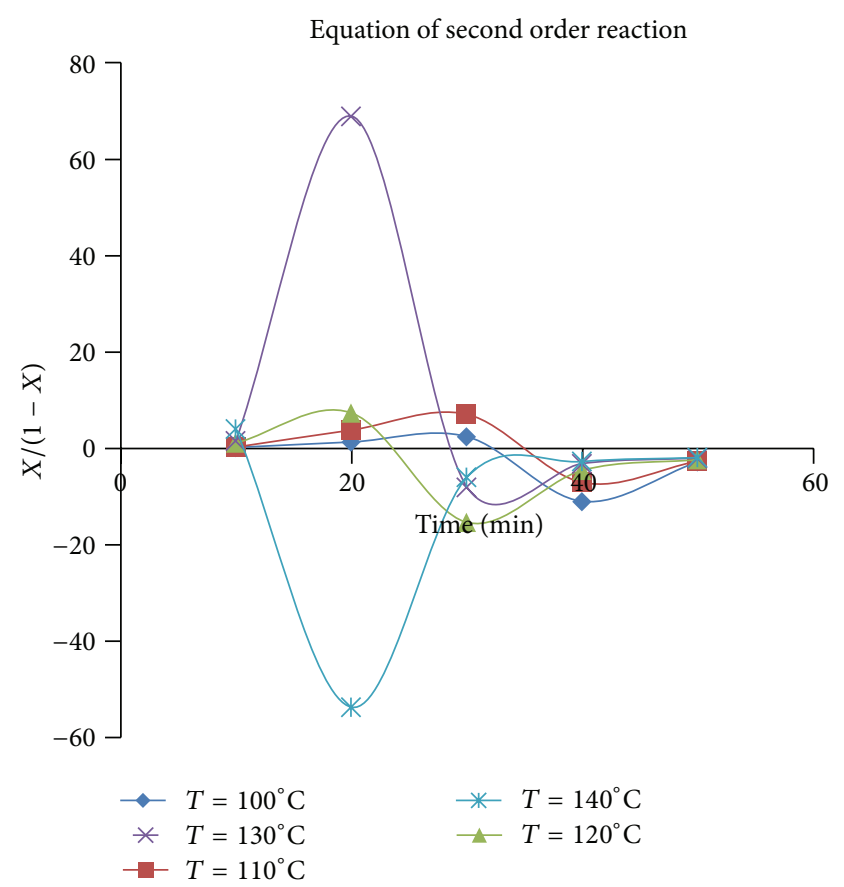

(b)

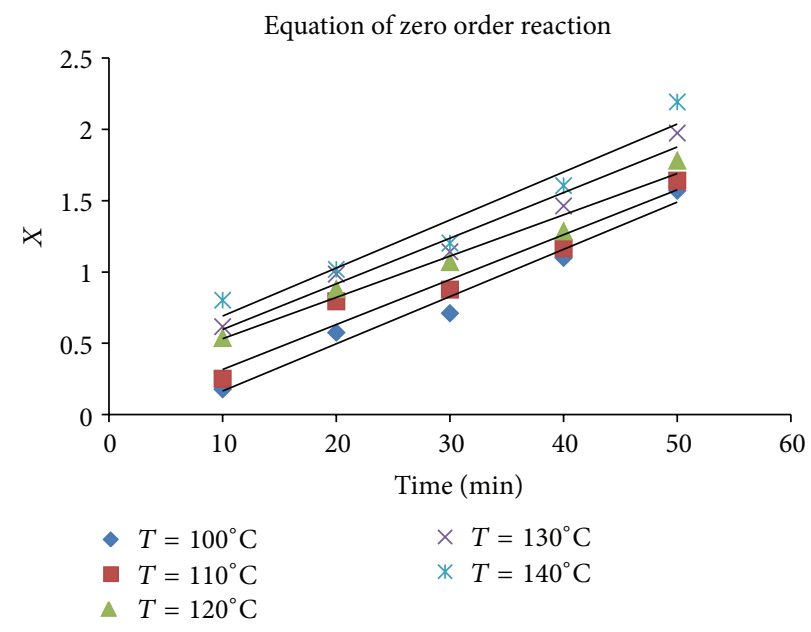

(c)

FIGURE 2: Plotting according to the equation of 1st, 2nd, and zero order reaction.

degradation of rigid-PVC pellets (R-PVC) with oxygen was zero order reaction. Consider

$$
\begin{gathered}
\ln \frac{1}{1-X}=K \cdot t, \quad \text { equation of first order reaction, } \\
\frac{X}{1-X}=K \cdot t, \quad \text { equation of second order reaction, } \\
X=K \cdot t, \quad \text { equation of zero order reaction, }
\end{gathered}
$$

where $X$ the weight loss at any time $t$ and $K$, the reaction constant.

It is also known that zero order reaction means that the thermal degradation does not depend on initial amount of polymer [18]. Moreover, the rate of reaction constant
TABLE 2: Rate of reaction constant $\ln (K)$ of recycled PVC resin at different temperatures $\left(100-140^{\circ} \mathrm{C}\right)$.

\begin{tabular}{lcc}
\hline Temperature $\left({ }^{\circ} \mathrm{C}\right)$ & $1 / T\left({ }^{\circ} \mathrm{K}\right)$ & Reaction rate constant, $\ln (\mathrm{K})$ \\
\hline 100 & 0.00268 & -3.5738 \\
110 & 0.00261 & -3.4506 \\
120 & 0.002544 & -3.2183 \\
130 & 0.00248 & -3.0603 \\
140 & 0.00242 & -2.8772 \\
\hline
\end{tabular}

increased with increasing temperatures. It may be attributed to the fact that the kinetic energy of molecules increased with increasing temperatures $[18,19]$, as shown in Table 2 and 
TABLE 3: $\ln (r / T)\left(\mathrm{g} / \mathrm{min}^{\circ} \mathrm{K}\right)$ of recycled PVC resin at different times (min) and at different temperatures $\left(100-140^{\circ} \mathrm{C}\right)$.

\begin{tabular}{lccccc}
\hline \multirow{2}{*}{$1 / T\left({ }^{\circ} \mathrm{K}\right)$} & & \multicolumn{3}{c}{$\ln (r / T)\left(\mathrm{g} / \mathrm{min}^{\circ} \mathrm{K}\right)$ At different curing time $(\mathrm{min})$} \\
& Time $=10 \mathrm{~min}$ & Time $=20 \mathrm{~min}$ & Time $=30 \mathrm{~min}$ & Time $=40 \mathrm{~min}$ & Time $=50 \mathrm{~min}$ \\
\hline 0.00268 & -9.94825 & -9.46949 & -9.6638 & -9.51551 & -9.38219 \\
0.00261 & -9.62852 & -9.17355 & -9.48085 & -9.48285 & -9.36512 \\
0.002544 & -8.89706 & -9.09667 & -9.30756 & -9.41183 & -9.3087 \\
0.00248 & -8.78497 & -9.00963 & -9.26774 & -9.3072 & -9.23095 \\
0.00242 & -8.54597 & -9.0009 & -9.24037 & -9.23906 & -9.15079 \\
\hline
\end{tabular}

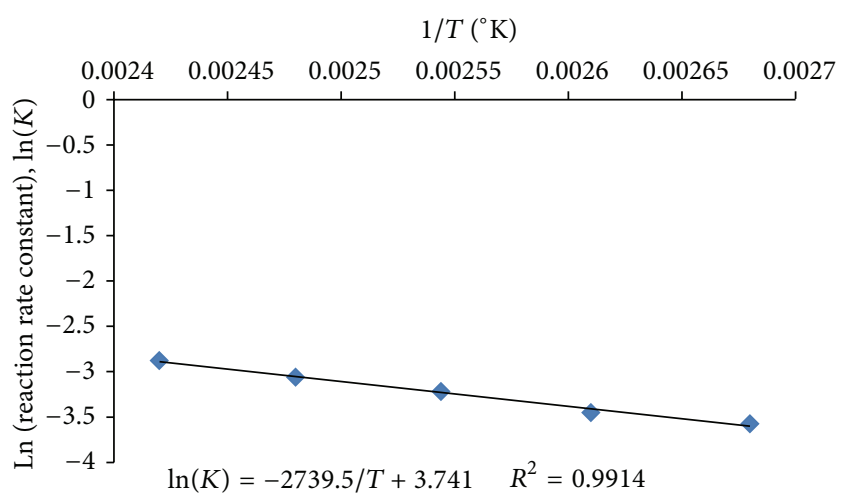

Figure 3: The $\ln (K)$ versus $(1 / T)\left({ }^{\circ} \mathrm{K}\right)$ of PVC resin at different temperature $\left(100-140^{\circ} \mathrm{C}\right)$.

Figure 3. Moreover, the activation energy $(E)$ can be found by the plotting of $\ln (K)$ versus $(1 / T)$ according to the following $[18]$ and the results were shown in Figure 3:

$$
\begin{gathered}
K=A e^{-E / R T,} \\
\ln (K)=-\frac{E}{R T}+\ln (A),
\end{gathered}
$$

where plotting of $\ln (K)$ versus (1/T) according to (8) gave a straight line, whereby its slope represented the activation energy of reaction $(E / R)$ while its intercept represented the preexponential factor $(A)$, as shown in Figure 3.

The activation energy of recycled PVC resin degradation was obtained from the slope of straight line in Figure 3 and it was found that the $E / R$ equals $2739.5^{\circ} \mathrm{K}(E=$ $22.78 \mathrm{~kJ} / \mathrm{mol}$ ) where it is a high value. For the reason that the activation energy of degradation reaction was a high value, the reaction progress was slow [18]. Similar result was reported by Jakubowicz [11], where the activation energy of PVC was found to be 11.2 and $29.1 \mathrm{~kJ} / \mathrm{mol}$ for $\mathrm{Ca} / \mathrm{Zn}$-stabilised and $\mathrm{Ba} / \mathrm{Cd} / \mathrm{Pb}$ stabilisers or pure $\mathrm{Pb}$ stabilizer composite, respectively. Yoshioka et al. [12] reported that the activation energy of oxidative degradation of rigid-PVC pellets (R-PVC) with oxygen was found to be $38.5 \mathrm{~kJ} / \mathrm{mol}$. The preexponential factor $(A)$ was 42.14011 , as shown in the following equation:

$$
\ln (K)=-\frac{2739.5}{T}+3.741
$$

To calculate the average enthalpy change $\left(\Delta H^{\circ}\right)$ and entropy change $\left(\Delta S^{\circ}\right)$ for range of temperatures $\left(100-140^{\circ} \mathrm{C}\right)$, plot $\ln (r / T)$ versus $1 / T$ according to the following gives a straight line.

The transition state equation $[20,21]$ is

$$
r=\frac{R T}{N \cdot h} * \operatorname{EXP}\left(\frac{\Delta S^{\circ}}{R}\right) * \operatorname{EXP}\left(-\frac{\Delta H^{\circ}}{R T}\right)
$$

where $r$ is the rate of reaction, $\Delta H^{\circ}$ the enthalpy of activation at standard condition, $\Delta S^{\circ}$ the entropy of activation at standard condition, $h$ Planck's constant, and $N$ the Avogadro number, respectively.

When rearranging (10) we obtained

$$
\frac{r}{T}=M * \operatorname{EXP}\left(-\frac{\Delta H^{\circ}}{R T}\right)
$$

where $M=R / N h * \operatorname{EXP}\left(\Delta S^{\circ} / R\right)$.

From taking the (ln) function to both sides of (11), we obtained:

$$
\ln \left(\frac{r}{T}\right)=-\frac{\Delta H^{\circ}}{(R * T)}+\ln (M)
$$

The slope of the straight line of (12) represents $\Delta H^{\circ} / R$ and the intercept represents $\ln (M)$, where $M$ is equal to $(R / N h *$ $\left.\operatorname{EXP}\left(\Delta S^{\circ} / R\right)\right)$, as shown in Table 3 and Figure 4.

As we show from Figure 4, the equations of the straight line are

$$
\begin{aligned}
& \ln \left(\frac{r}{T}\right)=-\frac{5634.5}{T}+5.1889, \quad \text { at Time }=10 \mathrm{~min}, \\
& \ln \left(\frac{r}{T}\right)=-\frac{1714}{T}-4.7848, \quad \text { at Time }=20 \mathrm{~min}, \\
& \ln \left(\frac{r}{T}\right)=-\frac{1645.6}{T}-5.2011, \quad \text { at Time }=30 \mathrm{~min}, \\
& \ln \left(\frac{r}{T}\right)=-\frac{1116.1}{T}-6.5488, \quad \text { at Time }=40 \mathrm{~min}, \\
& \ln \left(\frac{r}{T}\right)=-\frac{912.18}{T}-6.9644, \quad \text { at Time }=50 \mathrm{~min} .
\end{aligned}
$$

Therefore, from (13) the average of $\left(\Delta H^{\circ}\right)$ is equal to $9774.53 \mathrm{~J} / \mathrm{moL}$ and the the average of $\ln ((R / N h *$ $\left.\operatorname{EXP}\left(\Delta S^{\circ} / R\right)\right)$ is equal to -3.66204 . 


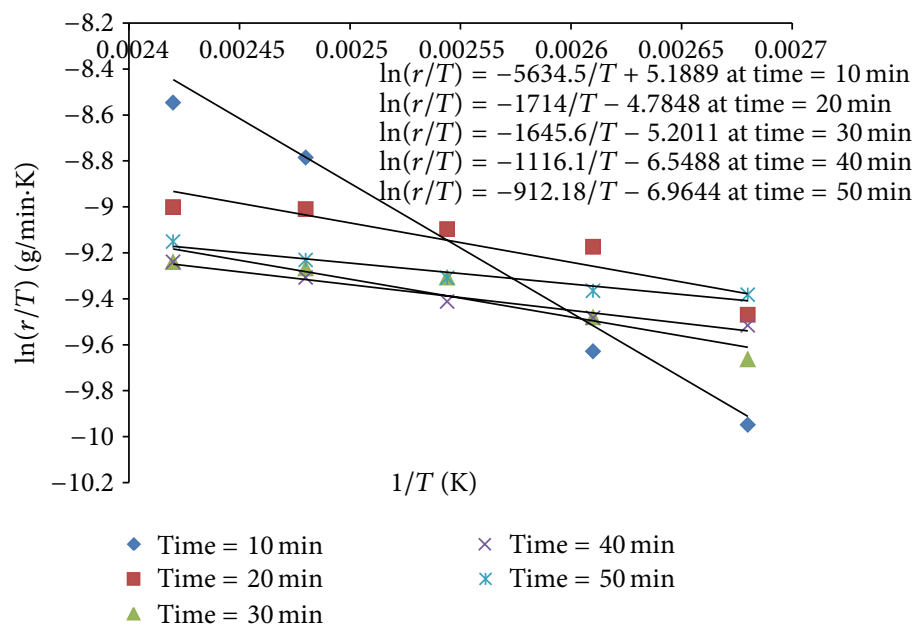

Figure $4: \ln (r / T)$ versus $(1 / T)$ of PVC resin at different time (min.) and at different temperature $\left(100-140^{\circ} \mathrm{C}\right)$.

\section{Conclusion}

The study of recycled PVC degradation kinetics revealed that the rate of reaction increased with increasing temperatures. Additionally, the rate constant $(K)$ of recycled PVC decomposition doubled from 0.028049 to $0.056292 \mathrm{~mol} \cdot \mathrm{L}^{-1} \cdot \mathrm{S}^{-1}$ when the temperatures were changed from 100 to $140^{\circ} \mathrm{C}$, respectively, and this rate constant $(K)$ value is very low. Therefore, the reaction proceeds slowly at these ranges of temperatures. It was found that the order of reaction was zero order in all ranges of temperatures $\left(100-140^{\circ} \mathrm{C}\right)$; thus the rate of degradation of recycled $\mathrm{PVC}$ resin was independent of the initial concentration of recycled PVC resin. The average enthalpy $\left(\Delta H^{\circ}\right)$ and entropy function $\left(\ln \left(\left(R / N h * \operatorname{EXP}\left(\Delta S^{\circ} / R\right)\right)\right)\right)$ of decomposition were 9774.53 and $-3.66204 \mathrm{~J} / \mathrm{mol}$, respectively. The activation energy of recycled PVC thermal degradation was $E / R=2739.5^{\circ} \mathrm{K}$ at different temperatures and it is very high. Therefore, the reaction of degradation was very slow at this range of temperatures $\left(100-140^{\circ} \mathrm{C}\right)$.

\section{Conflict of Interests}

The author declares that there is no conflict of interests.

\section{References}

[1] F. P. L. Mantia, Recycling of PVC and Mixed Plastic Waste, ChemTec Publishing, Toronto, Canada, 1996.

[2] Q. Zhang and H. Li, "Investigation on the thermal stability of PVC filled with hydrotalcite by the UV-vis spectroscopy," Spectrochimica Acta A, vol. 69, no. 1, pp. 62-64, 2008.

[3] K. Murata, M. Brebu, and Y. Sakata, "The effect of PVC on thermal and catalytic degradation of polyethylene, polypropylene and polystyrene by a continuous flow reactor," Journal of Analytical and Applied Pyrolysis, vol. 86, no. 1, pp. 33-38, 2009.

[4] T. Karayildirim, J. Yanik, M. Yuksel, M. Saglam, C. Vasile, and H. Bockhorn, "The effect of some fillers on PVC degradation," Journal of Analytical and Applied Pyrolysis, vol. 75, no. 2, pp. 112119, 2006.
[5] M. Brebu, T. Bhaskar, K. Murai, A. Muto, Y. Sakata, and M. A. Uddin, "The effect of PVC and/or PET on thermal degradation of polymer mixtures containing brominated ABS," Fuel, vol. 83, no. 14-15, pp. 2021-2028, 2004.

[6] R. Miranda, J. Yang, C. Roy, and C. Vasile, "Vacuum pyrolysis of commingled plastics containing PVC. I. Kinetic study, Polymer Degradation and Stability, vol. 72, no. 3, pp. 469-491, 2001.

[7] C. Tang, Y.-Z. Wang, Q. Zhou, and L. Zheng, "Catalytic effect of Al-Zn composite catalyst on the degradation of PVCcontaining polymer mixtures into pyrolysis oil," Polymer Degradation and Stability, vol. 81, no. 1, pp. 89-94, 2003.

[8] J. Halász, Z. Kónya, Z. T. Faragó, K. Siegert, and I. Kiricsi, "Degradation of pure and waste polyolefins and PVC in the presence of modified porous catalysts," Studies in Surface Science and Catalysis, vol. 174, no. 2, pp. 1021-1026, 2008.

[9] M. N. Radhakrishnan Nair, G. V. Thomas, and M. R. Gopinathan Nair, "Thermogravimetric analysis of PVC/ELNR blends," Polymer Degradation and Stability, vol. 92, no. 2, pp. 189-196, 2007.

[10] T. O. Egbuchunam, D. Balköse, and F. E. Okieimen, "Effect of zinc soaps of rubber seed oil (RSO) and/or epoxidised rubber seed oil (ERSO) on the thermal stability of PVC plastigels," Polymer Degradation and Stability, vol. 92, no. 8, pp. 1572-1582, 2007.

[11] I. Jakubowicz, "Effects of artificial and natural ageing on impactmodified poly(vinyl chloride) (PVC)," Polymer Testing, vol. 20, no. 5, pp. 545-551, 2001.

[12] T. Yoshioka, K. Furukawa, and A. Okuwaki, "Chemical recycling of rigid-PVC by oxygen oxidation in $\mathrm{NaOH}$ solutions at elevated temperatures," Polymer Degradation and Stability, vol. 67, no. 2, pp. 285-290, 2000.

[13] D. Sil and S. Chakrabarti, "Photocatalytic degradation of PVC$\mathrm{ZnO}$ composite film under tropical sunlight and artificial UV radiation: a comparative study," Solar Energy, vol. 84, no. 3, pp. 476-485, 2010.

[14] C. Yang, C. Gong, T. Peng, K. Deng, and L. Zan, "High photocatalytic degradation activity of the polyvinyl chloride (PVC)vitamin $\mathrm{C}(\mathrm{VC})-\mathrm{TiO}_{2}$ nano-composite film," Journal of Hazardous Materials, vol. 178, no. 1-3, pp. 152-156, 2010.

[15] J. Colombani, V. Labed, C. Joussot-Dubien et al., "High doses gamma radiolysis of PVC: mechanisms of degradation," Nuclear 
Instruments and Methods in Physics Research B, vol. 265, no. 1, pp. 238-244, 2007.

[16] K. Zhang, W. Cao, and J. Zhang, "Solid-phase photocatalytic degradation of PVC by tungstophosphoric acid-a novel method for PVC plastic degradation," Applied Catalysis A, vol. 276, no. 1-2, pp. 67-73, 2004.

[17] A. Castro, D. Soares, C. Vilarinho, and F. Castro, "Kinetics of thermal de-chlorination of PVC under pyrolytic conditions," Waste Management, vol. 32, no. 5, pp. 847-851, 2012.

[18] J. M. Simth, Chemical Engineering Kinetics, McGraw-Hill, Singapore, 3rd edition, 1981.

[19] A. A. Taker, Physical Chemistry for Polymer, Mosal University, Mosul, Iraq, 1984, Translated by Dr. A A. Mohammed.

[20] A. Ostovari, S. M. Hoseinieh, M. Peikari, S. R. Shadizadeh, and S. J. Hashemi, "Corrosion inhibition of mild steel in $1 \mathrm{M} \mathrm{HCl}$ solution by henna extract: a comparative study of the inhibition by henna and its constituents (Lawsone, Gallic acid, $\alpha$ d-Glucose and Tannic acid)," Corrosion Science, vol. 51, no. 9, pp. 1935-1949, 2009.

[21] A. K. Singh and M. A. Quraishi, "Effect of Cefazolin on the corrosion of mild steel in $\mathrm{HCl}$ solution," Corrosion Science, vol. 52, no. 1, pp. 152-160, 2010. 

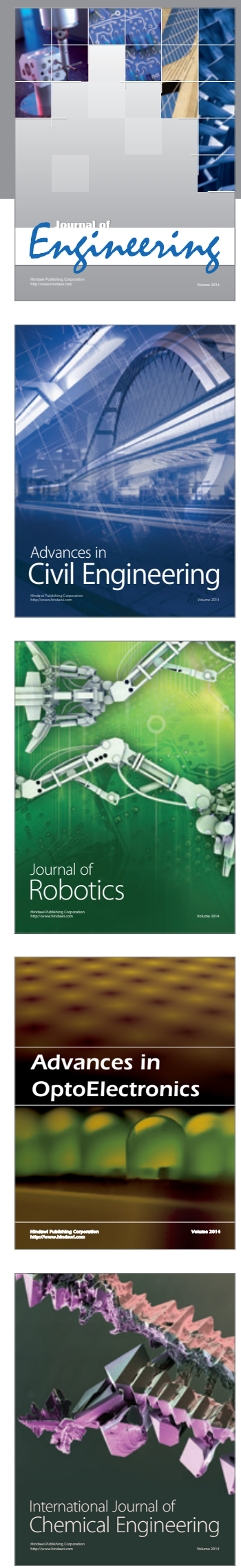

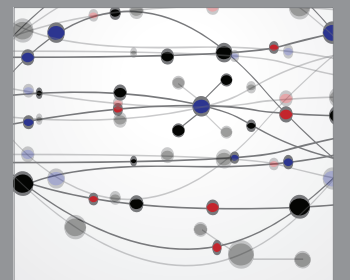

The Scientific World Journal
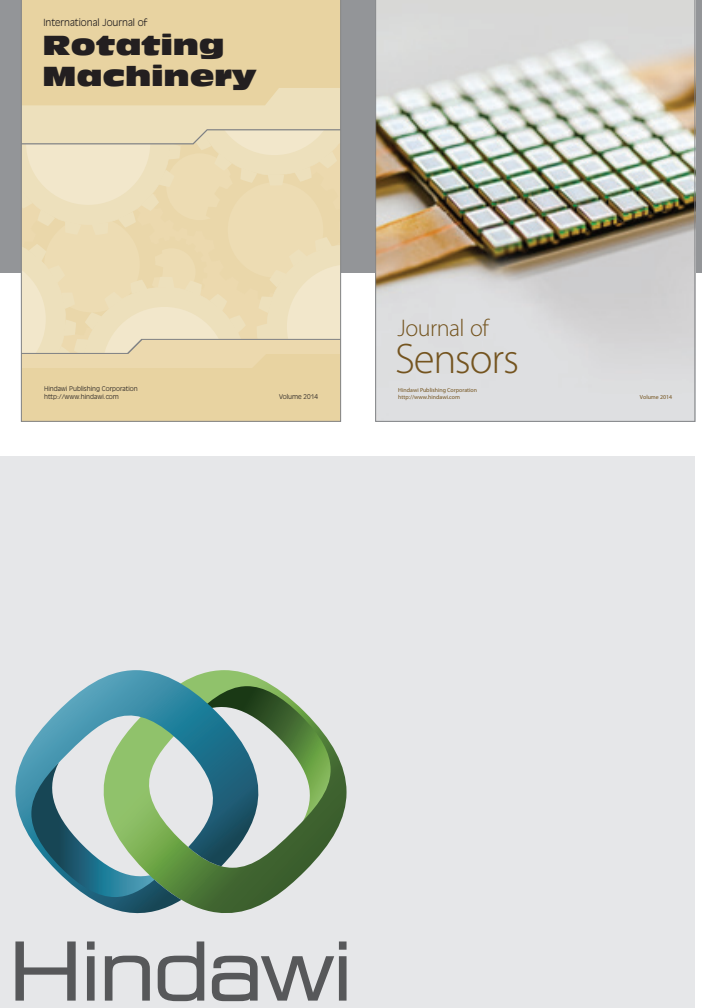

Submit your manuscripts at http://www.hindawi.com
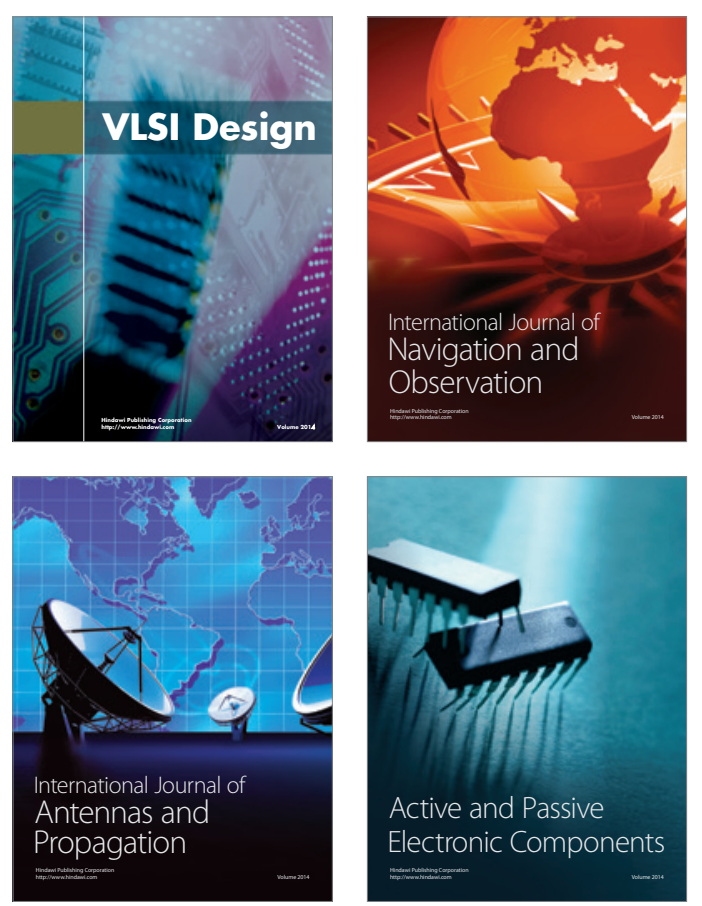
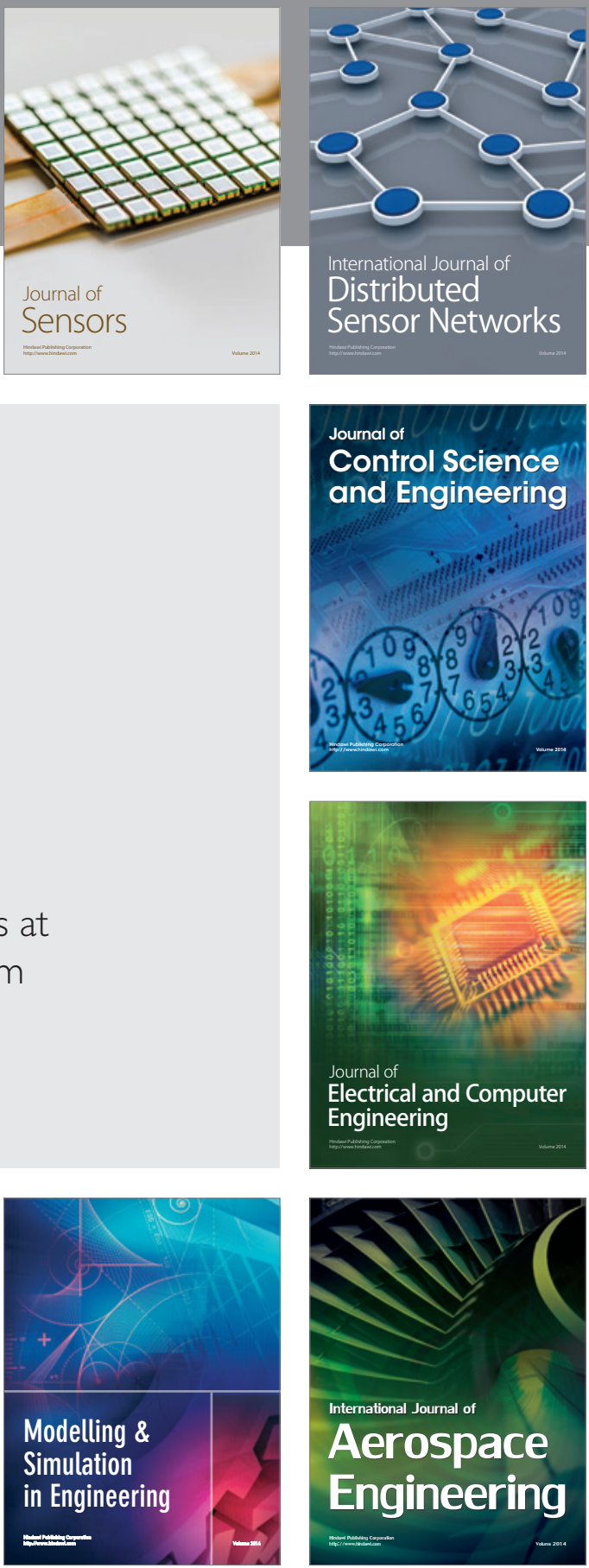

Journal of

Control Science

and Engineering
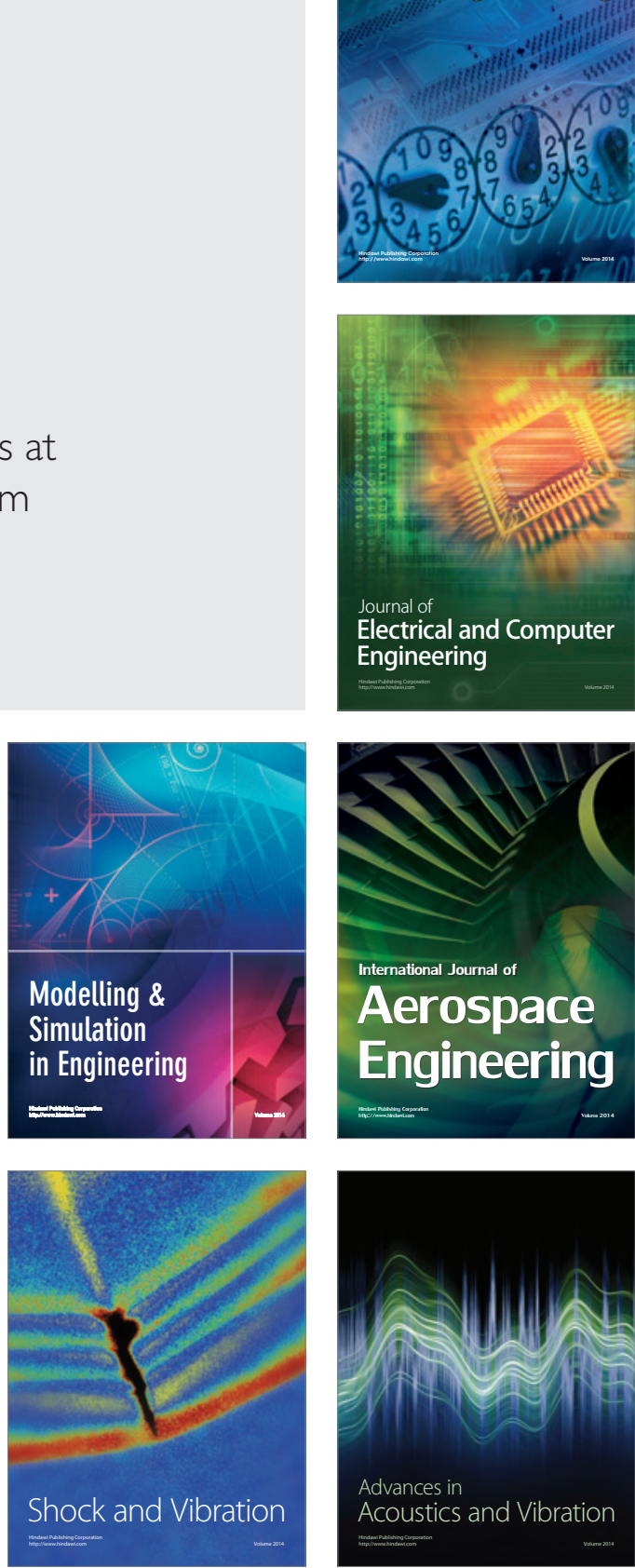